\title{
Prevalence of Malaria in a Tertiary Care Hospital at Mumbai, India
}

\author{
Nehal Mehta*, Chaya A. Kumar and Sujata Baveja \\ Department of Microbiology, LTMMC \&GH, Sion, Mumbai, India \\ *Corresponding author
}

\begin{abstract}
A B S T R A C T
\end{abstract}

\begin{tabular}{|l|}
\hline Ke y w or d s \\
Plasmodium vivax, \\
Malaria, Health \\
problem
\end{tabular}

Malaria is a major public health problem in India though it is both a preventable and treatable disease. Present study was undertaken to observe characteristics of Malaria, seasonal variation and prevalence of Malaria in tertiary care hospital in Mumbai. Present study was retrograde study which was conducted from 2011 to 2013 at Tertiary care hospital. Total 30,653 blood samples were collected from clinically suspected cases of malaria and tested by rapid malarial kit. A total 30,653 blood samples were tested from suspected cases of Malaria. Prevalence of Malaria varied from 7\% to 9\%. Most commonly involved age group was 21 to 30 years. Males were affected more compare to females. Marked seasonal variation was observed, maximum cases were seen from June to November. Most common species was Plasmodium vivax. Prevalence of malaria varied from $7 \%$ to $9 \%$ in present study. Malaria is a huge public health problem in terms of morbidity and burden on health care facilities. As the clinical signs \& symptoms of malaria mimic other infections, laboratory confirmation is essential and has to be included as a routine and its early diagnosis and treatment is necessary.

\section{Introduction}

Malaria is a major public health problem in India though it is both a preventable and treatable disease. As per the WHO estimates 207 million cases of malaria occurred globally in 2012 (uncertain range 135-287 million) and $6,27,000$ deaths (uncertain range 4,73,000$7,89,000$ ); about $80 \%$ of these cases were found in African countries and 13\% in South East Asia Region (SEAR) countries (World malaria report, 2013). India contributes to 61 $\%$ of malaria cases and $41 \%$ of malaria deaths in SEAR countries (World malaria report, 2011). In India Malaria is highly endemic.
(Roy et al., 2011) Hence its early diagnosis and proper treatment is essential.

Malaria is caused by four different species Plasmodium falciparum, Plasmodium vivax, Plasmodium malaria and Plasmodium ovale. The parasite life cycle involves two hosts during a blood meal, infected female anopheles mosquitoes inoculates sporozoites in to the human host which infect liver parenchyma cells, and forms schizoints which ruptures and release merozoites. After this initial replication in the live exoerythrocytic schizogony, the parasite undergoes asexual multiplications in the erythrocyte. Merozoites 
infect RBC; some merozoites differentiate in to sexual erythrocytic stages or gametocytes. Blood stage parasites are responsible the clinical manifestation of the disease. Recrudescence occurs in Plasmodium falciparums, Plasmodium malarias and relapses due to hypnozoite occurs in Plasmodium vivax and less commonly in Plasmodium ovale. Most transmission of malaria is by bite of mosquito however sometimes it can be transmitted by blood transfusion, contaminate syringes and needles. (Textbook of Medical parasitology protozoology \& Helminthology Text and color atlas) Now days control of malaria is directed at elimination of appropriate mosquitoes or stages of development. In addition, treatment of reservoir with active infections and prophylaxis of susceptible persons are also beneficial. Proper and timely implementation of vector control program is essential to reduce prevalence of malaria hence it is important to understand seasonal variation of Malaria

In India the problem is present not only in rural population but also in urban population. With this prospect the present study was carried out in our institute which crater major urban population for tertiary care. The objectives of this study were to find out prevalence of malaria, demographics of malaria cases and seasonal variation of malarial cases.

\section{Aim and Objectives}

Present Study was conducted to estimate serological prevalence of malaria from 2011 to 2013 and to study of demographics of cases.

\section{Materials and Methods}

This retrospective study was conducted in our institute from period of January 2011 to December 2013 after obtaining permission from institutional ethics committee. This study was carried out in the tertiary care level hospital in Mumbai City. All the fever cases undergone investigations for malarial parasites were included in present study from defined time period. Total 30,653 blood samples were tested by rapid malarial kit. Demographics of each case were studied. Data was analyzed statistically.

\section{Results and Discussion}

A total 30,653 blood samples were tested by rapid malarial kit from suspected cases of Malaria.

In 2011 prevalence of malaria was $8.34 \%$. Maximum cases of Malaria were seen in 2012, about $9.30 \%$ and in 2013 it was least, $7.35 \%$.

Malaria cases were seen throughout the year. It was observed that prevalence of malaria was increased from mid-June to November. It was observed that all age group were affected by Malaria however 21 to 30 years of age group was affected most.

Males were affected more compare to females.

Most common species was Plasmodium Vivax in all three years.

Plasmodium Vivax wax predominant throughout the year however incidence of Plasmodium Falciparum was increased from July to December compare to other months of the year.

Although overall numbers were large, this study had several limitations. All data were from single tertiary care hospital. Data were collected only from those patients who had done malaria test. The study relies on the assumption that quality of malaria diagnosis did not changed significantly during study period (Fig. 1 and 2; Table 1-6). 
Table.1 Prevalence of Malaria

\begin{tabular}{|c|c|c|c|}
\hline Year & Total tested samples & Positive samples & Percentage Positivity \\
\hline 2011 & 10022 & 836 & $8.34 \%$ \\
\hline 2012 & 10249 & 954 & $9.30 \%$ \\
\hline 2013 & 10382 & 763 & $7.35 \%$ \\
\hline
\end{tabular}

Table.2 Seasonal trend of Malaria

\begin{tabular}{|c|}
\hline January \\
\hline February \\
\hline March \\
\hline April \\
\hline May \\
\hline June \\
\hline July \\
\hline August \\
\hline September \\
\hline October \\
\hline November \\
\hline December \\
\hline
\end{tabular}

\begin{tabular}{|c|c|c|}
\hline 2011 & 2012 & 2013 \\
\hline $5.74 \%$ & $4.82 \%$ & $5.24 \%$ \\
\hline $5.26 \%$ & $2.62 \%$ & $2.10 \%$ \\
\hline $2.99 \%$ & $2.30 \%$ & $3.93 \%$ \\
\hline $3.35 \%$ & $3.77 \%$ & $3.15 \%$ \\
\hline $3.83 \%$ & $4.19 \%$ & $5.11 \%$ \\
\hline $3.59 \%$ & $4.09 \%$ & $9.04 \%$ \\
\hline $10.40 \%$ & $9.22 \%$ & $13.76 \%$ \\
\hline $16.15 \%$ & $18.13 \%$ & $15.73 \%$ \\
\hline $11.96 \%$ & $18.97 \%$ & $11.80 \%$ \\
\hline $16.50 \%$ & $13.41 \%$ & $11.27 \%$ \\
\hline $12.68 \%$ & $12.68 \%$ & $12.32 \%$ \\
\hline $7.54 \%$ & $5.77 \%$ & $6.55 \%$ \\
\hline
\end{tabular}

Table.3 Age wise distribution of malaria cases

\begin{tabular}{|c|}
\hline Less than 1 year \\
\hline 1 to 10 \\
\hline 11 to 20 \\
\hline 21 to 30 \\
\hline 31 to 40 \\
\hline 41 to 50 \\
\hline 51 to 60 \\
\hline 61 to 70 \\
\hline 71 to 80 \\
\hline 81 to 90 \\
\hline 91 to 100 \\
\hline
\end{tabular}

\begin{tabular}{|c|c|c|}
\hline 2011 & 2012 & 2013 \\
\hline $1.67 \%$ & $1.94 \%$ & $1.17 \%$ \\
\hline $10.55 \%$ & $8.55 \%$ & $6.24 \%$ \\
\hline $12.70 \%$ & $17.71 \%$ & $20.05 \%$ \\
\hline $30.70 \%$ & $31.55 \%$ & $31.10 \%$ \\
\hline $18.59 \%$ & $18.02 \%$ & $15.99 \%$ \\
\hline $12.70 \%$ & $10 \%$ & $12 \%$ \\
\hline $7.34 \%$ & $8.07 \%$ & $8.29 \%$ \\
\hline $3.96 \%$ & $4.09 \%$ & $4.15 \%$ \\
\hline $1.20 \%$ & $1.36 \%$ & $1.18 \%$ \\
\hline $0.48 \%$ & $0.31 \%$ & $0.66 \%$ \\
\hline 0 & 0 & $0.13 \%$ \\
\hline
\end{tabular}

Table.4 Sex wise distribution of malaria cases

\begin{tabular}{|c|c|c|c|}
\hline & Male & Female & Male: Female \\
\hline $\mathbf{2 0 1 1}$ & 630 & 206 & $3: 1$ \\
\hline $\mathbf{2 0 1 2}$ & 765 & 189 & $4: 1$ \\
\hline $\mathbf{2 0 1 3}$ & 619 & 144 & $4.3: 1$ \\
\hline
\end{tabular}


Table.5 Various species of malarial parasite

\begin{tabular}{|c|c|c|c|}
\hline & P.VIVAX & P.FALCIPARUM & MIXED \\
\hline 2011 & $66.50 \%$ & $29.90 \%$ & $3.58 \%$ \\
\hline 2012 & $54.19 \%$ & $40.15 \%$ & $5.66 \%$ \\
\hline 2013 & $71.70 \%$ & $27.79 \%$ & $0.52 \%$ \\
\hline
\end{tabular}

Table.6 Seasonal variation of various species of malarial parasite

\begin{tabular}{|l|l|l|l|l|l|l|l|l|l|}
\hline \multicolumn{1}{|c|}{ Month } & \multicolumn{3}{|c|}{2011} & \multicolumn{3}{|c|}{2012} & \multicolumn{2}{|c|}{2013} \\
\hline January & $81.25 \%$ & $16.67 \%$ & $2.08 \%$ & $78.26 \%$ & $13.04 \%$ & $8.70 \%$ & $80 \%$ & $20 \%$ & 0 \\
\hline February & $95.45 \%$ & $2.27 \%$ & $2.27 \%$ & $92 \%$ & 0 & $8 \%$ & 87.5 & $12.5 \%$ & 0 \\
\hline March & $92 \%$ & $8 \%$ & 0 & $90.91 \%$ & $9.09 \%$ & 0 & $96.67 \%$ & $3.33 \%$ & 0 \\
\hline April & $89.29 \%$ & $7.14 \%$ & $3.57 \%$ & $91.67 \%$ & $8.33 \%$ & 0 & $91.67 \%$ & $8.33 \%$ & 0 \\
\hline May & $90.63 \%$ & $6.25 \%$ & $3.13 \%$ & $92.68 \%$ & $4.88 \%$ & $2.44 \%$ & $94.87 \%$ & $5.13 \%$ & 0 \\
\hline June & $86.67 \%$ & $6.67 \%$ & $6.67 \%$ & $77.5 \%$ & $15 \%$ & $7.5 \%$ & $86.96 \%$ & $8.7 \%$ & $4.35 \%$ \\
\hline July & $67.81 \%$ & $29.89 \%$ & $2.30 \%$ & $62.5 \%$ & $27.27 \%$ & $10.23 \%$ & $61.90 \%$ & $38.10 \%$ & 0 \\
\hline August & $53.73 \%$ & $46.27 \%$ & 0 & $50.87 \%$ & $36.42 \%$ & $12.72 \%$ & $76.67 \%$ & $23.33 \%$ & 0 \\
\hline September & $52 \%$ & $47 \%$ & $1 \%$ & $26.52 \%$ & $67.96 \%$ & $5.52 \%$ & 70 & 30 & 0 \\
\hline October & $62.32 \%$ & $30.43 \%$ & $7.25 \%$ & $39.84 \%$ & $58.59 \%$ & $1.56 \%$ & $58.87 \%$ & $45.98 \%$ & $1.15 \%$ \\
\hline November & $57.55 \%$ & $34.90 \%$ & $7.5 \%$ & $52.06 \%$ & $46.28 \%$ & $1.65 \%$ & $52.13 \%$ & $47.87 \%$ & 0 \\
\hline December & $66.67 \%$ & $30.16 \%$ & $3.17 \%$ & $56.36 \%$ & $41.82 \%$ & $1,81 \%$ & $78 \%$ & $22 \%$ & 0 \\
\hline
\end{tabular}

*Plasmodium Falciparum

Fig.1 Prevalence of Malaria

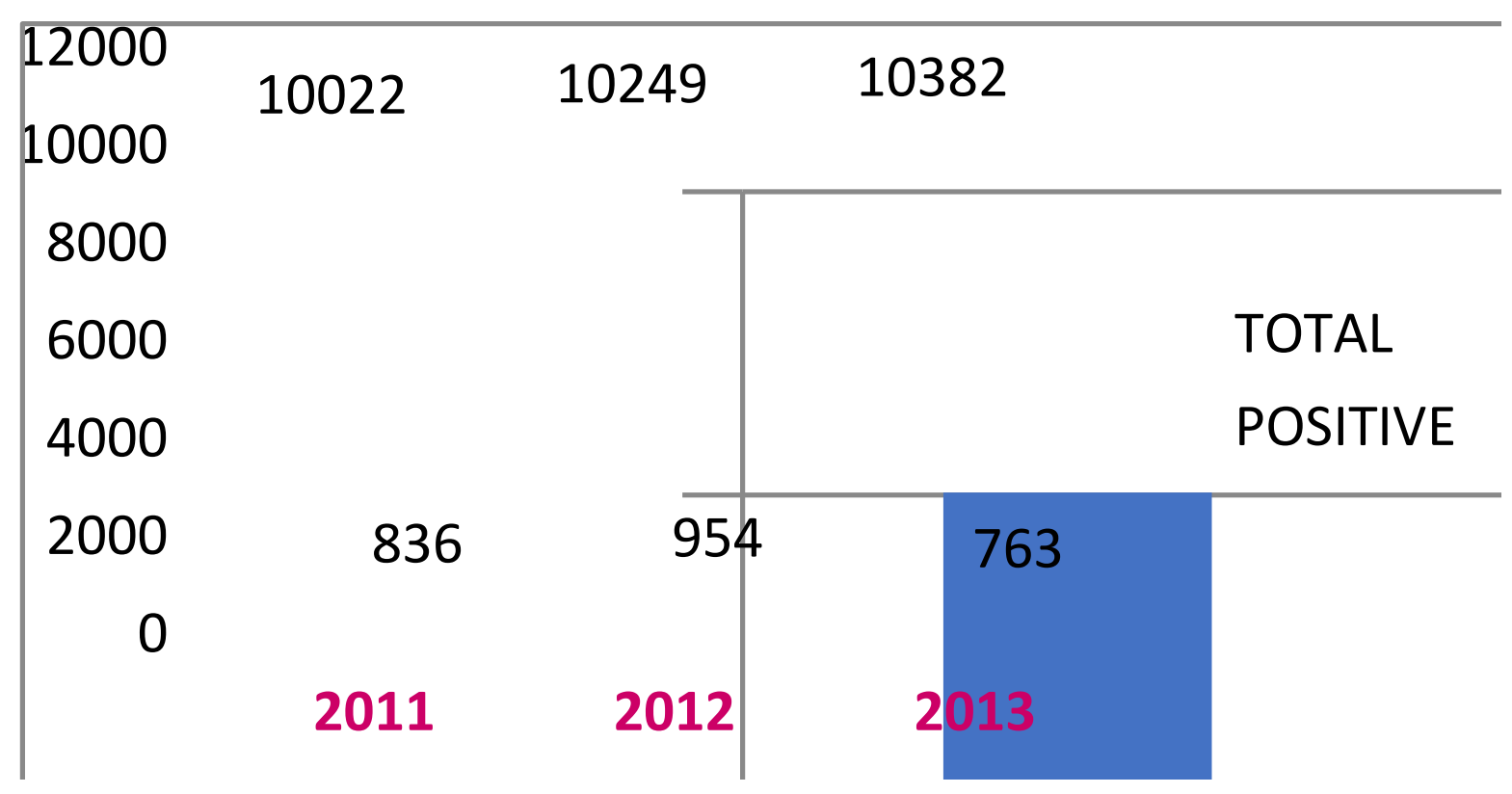


Fig.2 Seasonal trend of Malaria

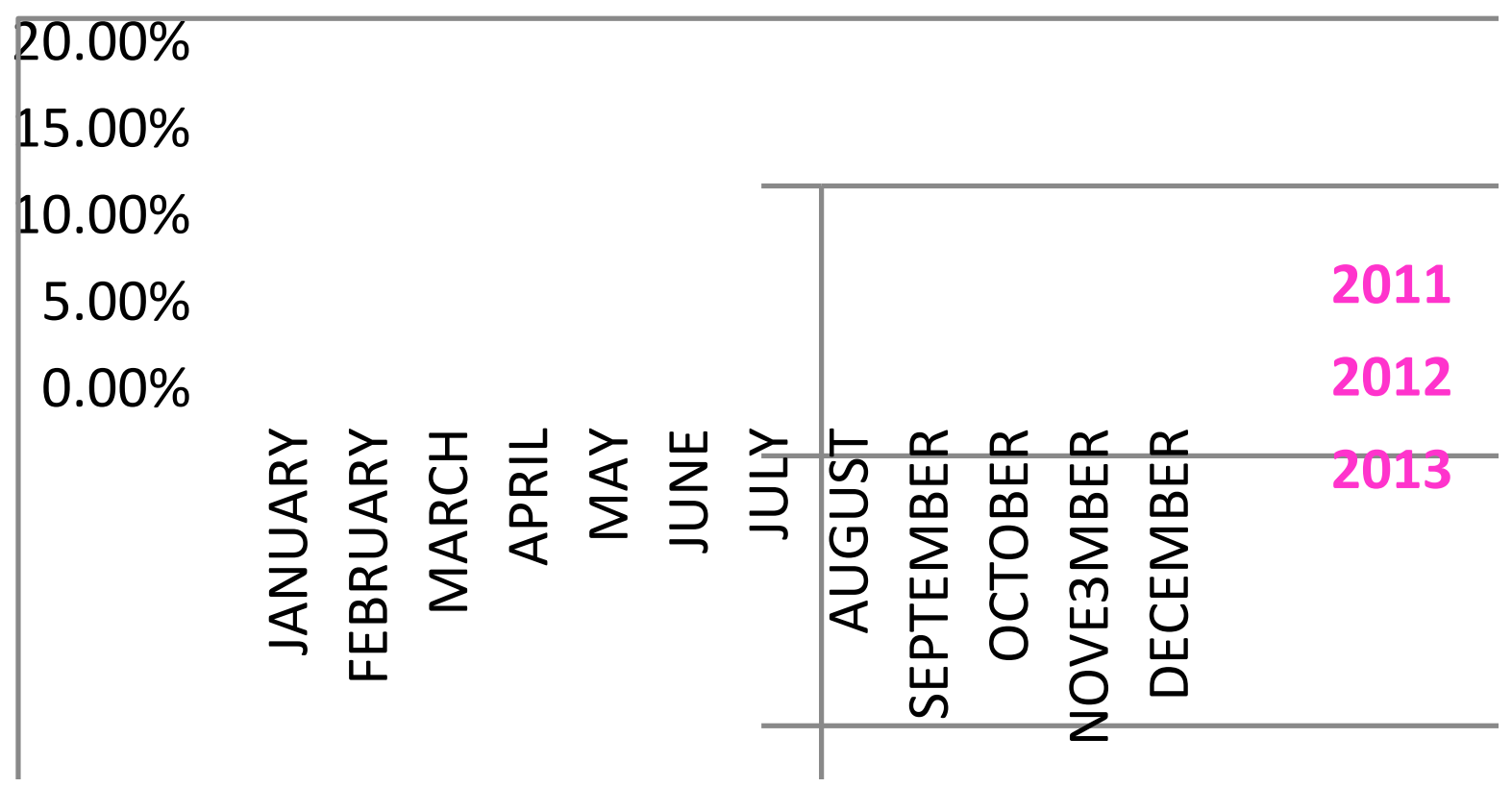

Prevalence of malaria varied from $7 \%$ to $9 \%$ in present study. In various study it was observed that prevalence of malaria varied from 3\% to 22\% (Paltial Palat et al., 2013), (Patil and Kumar, 2011), (Pardal et al., 2009), (Anirudh et al., 2013), (Singh et al., 2009), (Singh et al., 2015).

It was observed that cases of malaria increases in monsoon and post monsoon, due to post shower effect. Similar finding was observed in study done by (Paltial Palat et al., 2013). Climate in Mumbai is hot and humid during monsoon, due to which breeding of mosquitoes increases which leads to increase cases of Malaria.

Most commonly infected age group was 21 to 30 years of age. Similar finding was seen in study done by (Paltial Palat et al., 2013). As this is young adult group, physically active, hence more prone to contact with vector.

In present study males were more infected when compared to females. Similar finding was observed in study done by (Paltial Palat et al., 2013). Higher incidence of malaria in male can be due to their outdoor activity and bringing male more frequently compare to female to health services.

Maximum cases were due to Plasmodium Vivax throughout the study however few cases of Plasmodium falciparum and mixed infection were seen. Similar finding was observed in study done by (Singh et al., 2015) During monsoon prevalence of Plasmodium Falciparum was increased compare to other months of the year. Similar finding was seen in study conducted by (Paltial Palat et al., 2013) The difference in prevalence of Plasmodium vivax and Plasmodium falciparum in different areas can be due to presence of endemicity of particular type and higher relapses in vivax type.

Malaria is a huge public health problem in terms of morbidity and burden on health care facilities, accounting for the increasing percentage of outpatient consultations in most health facilities in different regions in Mumbai. As the clinical signs \& symptoms of 
malaria mimic other infections, laboratory confirmation is essential and has to be included as a routine.Intensive malaria control activity should be instituted from mid-June to mid-November in areas of increased prevalence

\section{References}

Anirudh R. Acharya et al., Trend of malaria incidence in the state of Karnataka, India for 2001 to 2011, Arch. Appl. Sci. Res., 2013, 5 (3):104-111

Paltial Palat et al., Rising Incidence of Malaria in Ahmedabad, International Journal of Medical Science and Public Health, 2013, 2(2): 546 to 549.

Pardal MPS, Bhalwar R, Mehta VK, Mahendraker A, Mehta AK. Malaria in Assam: A Challenge. Indian Journal of Community Medicine: Official Publication of Indian Association of Preventive \& Social Medicine. 2009; 34(2): 94-96. doi: 10.4103/09700218.51225 .

Patil RR, and Kumar RK. World bank EMCP malaria project in Orissa, India - A field reality. Tropical Parasitology. 2011; 1(1): 26-29. doi:10.4103/22295070.72111 .
Roy SB, Sarkar RR, Sinha S. Theoretical investigation of malaria prevalence in two Indian cities using the response surface method. Malaria Journal, 2011.

Singh G, Urhekar AD, Maheshwari U, Sharma S, Raksha (2015) Prevalence of Malaria in a Tertiary Care Hospital in Navi Mumbai, India. J Bacteriol Parasitol 6: 221. doi: 10.4172/21559597.1000221

Singh N, Dash AP, Thimasarn K. Fighting malaria in Madhya Pradesh (Central India): Are we loosing the battle? Malaria Journal. 2009; 8:93. doi: 10.1186/1475-2875-8-93.

Textbook of Medical parasitology protozoology \& Helminthology Text and color atlas, $4^{\text {th }}$ Edition, Subhash Chandra Parija, pg no: 109 to 143

World malaria report 2011. Geneva: World Health Organization; [accessed on March 11, 2014]. WHO. Available from: http://www.who.int/malaria/world _malaria _report_2011/9789241564403_eng.pdf.

World malaria report 2013. Geneva: World Health Organization; 2013. [accessed on March 11, 2014]. WHO. Available from: www.who.int/iris/bitstream/1066 5/97008/1/9789241564694_eng.pdf.

\section{How to cite this article:}

Nehal Mehta, Chaya A. Kumar and Sujata Baveja. 2018. Prevalence of Malaria in a Tertiary Care Hospital at Mumbai, India. Int.J.Curr.Microbiol.App.Sci. 7(09): 1974-1979. doi: https://doi.org/10.20546/ijcmas.2018.709.239 